\title{
Serotonin 2A Receptor Gene Polymorphism in Korean Children with Attention-Deficit/Hyperactivity Disorder
}

\author{
Soo-Churl Cho', Jung-Woo Son ${ }^{\bowtie}$, Boong-Nyun Kim¹, Jae-Won Kim¹, Hee-Jeong Yoo ${ }^{3}$, \\ Jun-Won Hwang ${ }^{4}$, Dae-Yeon $\mathrm{Cho}^{5}$, Un-Sun Chung ${ }^{6}$ and Tae-Won Park ${ }^{7}$ \\ 'Department of Child and Adolescent Psychiatry, Seoul National University College of Medicine, Seoul, Republic of Korea \\ ${ }^{2}$ Department of Neuropsychiatry, College of Medicine, Chungbuk National University, Cheongju, Republic of Korea \\ ${ }^{3}$ Department of Psychiatry, Seoul National University Bundang Hospital, Seongnam, Republic of Korea \\ ${ }^{4}$ Department of Neuropsychiatry, Kangwon National University School of Medicine, Chuncheon, Republic of Korea \\ ${ }^{5}$ LabGenomics Clinical Research Institute, LabGenomics, Seoul, Republic of Korea \\ ${ }^{6}$ Department of Psychiatry, School of Medicine, Kyungpook National University, Daegu, Republic of Korea \\ ${ }^{7}$ Department of Neuropsychiatry, College of Medicine, Chonbuk National University, Jeonju, Republic of Korea
}

Objective The purpose of this study was to investigate the association between the T102C polymorphism in the serotonin $2 \mathrm{~A}$ receptor gene and attention-deficit/hyperactivity disorder (ADHD) in Korean patients.

Methods A total of 189 Korean children with ADHD as well as both parents of the ADHD children and 150 normal children participated in this study. DNA was extracted from blood samples from all of the subjects, and genotyping was conducted. Based on the allele and genotype information obtained, case-control analyses were performed to compare the ADHD and normal children, and Transmission disequilibrium tests (TDTs) were used for family-based association testing (number of trios=113). Finally, according to the significant finding which was showed in the case-control analyses, the results of behavioral characterastics and neuropsychological test were compared between ADHD children with and without the $\mathrm{C}$ allele.

Results In the case-control analyses, statistically significant differences were detected in the frequencies of genotypes containing the $\mathrm{C}$ allele $\left(\chi^{2}=4.73, p=0.030\right)$. In the family-based association study, TDTs failed to detect linkage disequilibrium of the T102C polymorphism associated with $\mathrm{ADHD}$ children. In the $\mathrm{ADHD}$ children, both the mean reaction time and the standard deviation of the reaction time in the auditory continuous performance test were longer in the group with the $\mathrm{C}$ allele compared to the group without the $\mathrm{C}$ allele.

Conclusion The results of this study suggest that there is a significant genetic association between the T102C polymorphism in the serotonin $2 \mathrm{~A}$ receptor gene and ADHD in Korean children.

Psychiatry Investig 2012;9:269-277

Key Words ADHD, Genetic study, Serotonin, 5-HT2A receptor, Auditory attention.

\section{INTRODUCTION}

Studies on the causes and pathogenesis of attention-deficit/ hyperactivity disorder (ADHD) are actively underway. As many researches have reported that $\mathrm{ADHD}$ is heritable in 60$100 \%$ of cases, ${ }^{1}$ the importance of conducting molecular genetic studies on $\mathrm{ADHD}$ is higher than ever.

Received: December 30, 2011 Revised: April 18, 2012

Accepted: April 25, 2012 Available online: September 6, 2012

$\triangle$ Correspondence: Jung-Woo Son, $\mathrm{MD}, \mathrm{PhD}$

Department of Neuropsychiatry, College of Medicine, Chungbuk National University, 52 Gaesin-dong, Heungdeok-gu, Cheongju 361-763, Republic of Korea Tel: +82-43-269-6182, Fax: +82-43-267-7951

E-mail: mammosss@hanmail.net

(c) This is an Open Access article distributed under the terms of the Creative Commons Attribution Non-Commercial License (http://creativecommons.org/licenses/by$\mathrm{nc} / 3.0$ ) which permits unrestricted non-commercial use, distribution, and reproduction in any medium, provided the original work is properly cited.
Association analysis is the most widely used molecular genetic research method in studies of human disease because it is more likely to detect genes of interest compared to other methods as long as the candidate genes are selected properly. Family-based association analysis has also been used frequently in this type of investigation in recent years. The transmission disequilibrium test (TDT) is one of the representative methods for family-based association analysis. ${ }^{2,3}$

Similar to analyses that have been used to evaluate other mental disorders, molecular genetic studies involving ADHD have focused on several neurotransmitters which play major roles in the pathophysiology of these diseases. Consequently, the researches have been conducted on the candidate genes of all components that comprise the dopaminergic system, such as the studies for dopamine transporter 1, dopamine receptor 
types 1-5 (D1, D2, D3, D4, D5), monoamine oxidase (MAO), and catechol-O-methyltransferase (COMT). Moreover, in recent years, studies related to the norepinephrinergic system in ADHD have also been reported.,

In contrast, the molecular genetic interest in the serotonergic system has been relatively small, which is attributed to the lack of consistent results from the early studies on the relationship between ADHD and serotonergic substances. Nevertheless, in the late 1990s, it was reported that the serotonergic system is associated with aggressive behavior in children with ADHD. ${ }^{6,7}$ In particular, one study using dopamine transporter knock-out mice, which are animal models for hyperactivity in $\mathrm{ADHD}$, demonstrated that the serotonergic system is involved not only in regulating aggressive behaviors associated with $\mathrm{ADHD}$ but also in regulating hyperactivity. ${ }^{8}$ Based on these findings, Quist and Kennedy ${ }^{9}$ claimed that serotonergic substances show widely variable correlations with several ADHD symptoms, similar to the results of previous studies on serotonin-related substances in the blood, urine, or cerebrospinal fluid of ADHD patients.

The serotonergic candidate genes that have been studied primarily so far include the serotonin transporter (5-HTT), serotonin 2A-type receptor (5-HTR2A), and serotonin 1B-type receptor (5-HTR1B).

The 5-HTR2A is a post-synaptic receptor. 5-HTR2A antagonist reduced hyperactivity induced by amphetamine, which is a representative substance of the dopaminergic system. ${ }^{10}$ Furthermore, 5-HT neurons innervate dopamine neurons either directly via postsynaptic 5-HTR2A on the dopamine neuron or indirectly via 5-HTR2A receptors on GABA interneurons. When serotonin is released onto the postsynaptic 5-HTR2A, it would be like a brake on dopamine release, so the dopamine neuron would be inhibited. ${ }^{11}$ On the basis of these reports, researchers studying the molecular genetics of ADHD became interested in the interaction between 5-HTR$2 \mathrm{~A}$ and the dopaminergic system.

The 5-HTR2A gene is located on chromosome 13q14-q21, and the polymorphisms in this gene that are most frequently found in the general population are T102C, A-1438G, and His452Tyr. Among them, A-1438G was found to be a mutation in the gene promoter region, ${ }^{12}$ while His452Tyr is located at the intracellular C-terminal end of the protein, and the secondary structure of the receptor protein may be altered by this mutation. ${ }^{13}$ Furthermore, T102C and A-1438G have been reported to show strong linkage disequilibrium. ${ }^{14}$

There have been a number of studies involving ADHD and 5-HTR2A gene polymorphisms. One such study by Quist et al. ${ }^{15}$ revealed selective transmission of the 452Tyr allele of the His452Tyr polymorphism, which was not observed for the T102C polymorphism. However, a study by Hawi et al. ${ }^{16}$ re- ported that the $452 \mathrm{His}$ allele was selectively transmitted instead. Furthermore, Zoroglu et al. ${ }^{17}$ reported that no significant results were found in both T102C and A-1438G polymorphisms. On the other hand, researchers have reported that selective transmissions were found in T102C polymorphisms in Chinese Han children with ADHD. ${ }^{18}$

Thus, a number of studies addressing the involvement of the 5-HTR2A polymorphism in ADHD have been conducted, but their results are not yet clear. In particular, many of these studies involve non-Asians, such as Caucasians. Other than the two studies conducted in China, few investigations have targeted Asian populations. Therefore, additional studies within the Korean population are necessary. Furthermore, few of the previous studies have reported results about relationship between the neuropsychological/behavioral characteristics and the genotypes in ADHD patients.

Therefore, in this study, we aimed to identify the association between the 5-HTR2A gene polymorphism with ADHD in Korean patients using a case-control association analysis and family-based TDT, as well as to investigate changes in neuropsychological and behavioral characteristics, depending on the genotype or allele frequencies of the $\mathrm{ADHD}$ patients.

\section{METHODS}

\section{Research subjects}

ADHD outpatients who visited the Child and Adolescent Psychiatric Departments at 4 hospitals were selected for the study based on the following factors: 1) an age more than 5 years old; 2) diagnosis of ADHD using the DSM-IV ${ }^{19}$ diagnostic criteria and semi-structured interviews; and 3) a total score on the Parent ADHD Rating Scale (Korean ADHD Rating Scale; K-ARS $)^{20}$ under the $90^{\text {th }}$ percentile cutoff point. On the other hand, patients with the following conditions were excluded from the study: 1) an IQ of 70 or less; 2) a congenital genetic disorder; 3) a history of acquired brain injury, such as cerebral palsy; 4) a seizure disorder or other neurological disease; 5) a developmental disability, such as autism; and 6) schizophrenia, bipolar disorder, other childhood psychosis, Tourette's syndrome, speech disorder, or severe learning disability. 189 ADHD patients who satisfied these selection and exclusion criteria and agreed to cooperate in the study, and 113 pairs of biological parents of these patients who were able to cooperate in the blood sampling and other research were selected as the study subjects. Because 3 patients did not receive results from the genetic analysis due to an error during the analysis, they were excluded from the association analysis; therefore, a total of 186 patients were assessed.

As the normal control group, 150 students were selected from one elementary school in Seoul and another in Jeonju 
after excluding children according to the following criteria: 1) having major medical/neurological/psychiatric diseases, as determined through parent surveys; 2 ) exhibiting serious behavioral problems, as determined through telephone consultations with their teachers; 3 ) presenting a total K-ARS score falling above the $90^{\text {th }}$ percentile cutoff point; and 4) having an IQ of 70 or less (overall intelligence was estimated through vocabulary and block design subtests from the KEDI-WISC intelligence assessment). ${ }^{21}$

This study was approved by the Bioethics Committee of the College of Medicine at Chungbuk National University. A written description of the research protocol was provided to the parents and children who decided to participate in the study, and written consent forms were obtained.

\section{Clinical and neuropsychological assessments}

The clinical and neuropsychological assessment tools used in this study were as follows:

\section{Kiddie-Schedule for Affective Disorders and} Schizophrenia-Present and Lifetime Version-Korean Version (K-SADS-PL-K)

This is a semi-structured interview tool that was designed to assess the current and continuing morbidities of 32 child and adolescent psychiatric disorders and the severity of the symptoms based on DSM-IV diagnostic criteria. ${ }^{22}$ A version of this tool has been translated into Korean. Using this tool, we examined the diagnoses of the ADHD children, their subtype classifications, and the presence of any coexisting diseases.

\section{Korean Educational Development Institute-Wechsler Intelligence Scale for Children (KEDI-WISC) ${ }^{23}$}

As an intelligence assessment tool for children and adolescents, it was modified and supplemented using the American WISC-R so that the items thought to have cultural differences were made to fit Korean society. This study used 3 variables of verbal IQ, performance IQ, and full-scale IQ.

\section{Korean ADHD Rating Scale-IV for Parents and Teachers (K-ARS) ${ }^{20}$}

This tool has been designed to assess ADHD symptoms in school-age children, and a Korean version has been developed and standardized. This instrument consists of a total of 18 questions and is arranged such that the total score for the odd-numbered questions measures the symptoms of attention deficit disorder, while the total score for the even-numbered questions measures the symptoms of hyperactive-impulsive disorder.

\section{Korean Child Behavior Checklist (K-CBCL)}

This tool, which was developed by Achenbach et al., ${ }^{24}$ measures parents' observations of various aspects of their children's behaviors and has been developed and standardized for the Korean population. The K-CBCL consists of 2 types of scales to assess social competence and problem behavior. Among these scales, the problem behavior scale consists of 13 subscales, which can be divided into internalizing problems subscales and an externalizing problems subscales. In this study, we used scores from 3 types of scales, including an internalizing problems subscale, an externalizing problems subscale, and an overall problem behavior scale.

\section{Continuous Performance Test (CPT)}

The CPT is a very important tool for assessing attention, and in this study, we used the ADHD Diagnostic System, ${ }^{25}$ which was developed in Korea. This system consists of a visual CPT and an auditory CPT. The following indicators were calculated: the omission error, the commission error, the mean reaction time, and the standard deviation of reaction time. We used all indicators in this study.

\section{Genetic analysis}

\section{DNA extraction and storage}

Approximately $10 \mathrm{cc}$ of whole blood was collected from each subject in every group (patient, parent, and control groups) who participated in the genetic analysis, and the blood samples were stored at $-20^{\circ} \mathrm{C}$. Genomic DNA was extracted from frozen blood using the G-DEX ${ }^{\mathrm{TM}} \mathrm{II}$ Genomic DNA Extraction Kit (Intron, Korea).

\section{Analysis of candidate genes}

The 5-HTR2A gene T102C polymorphism was analyzed using a chip-based MALDI-TOF mass spectrometry platform (Sequenom, Inc., CA). The general test method described in the basic protocol provided by the manufacturer was used.

\section{PCR}

PCR primers (T102C-F: 5'-ACG TTG GAT GTG ATG ACA CCA GGC TCT ACA, T102C-R: 5'-ACG TTG GAT GAG AGA CAC GAC GGT GAG AGG) were designed using the Primer3 program (http://www-genome.wi.mit.edu/ cgi-bin/primer/primer3_www.cgi). PCRs were carried out in $5 \mu \mathrm{L}$ of 1X PCR buffer (TAKARA, Japan) that contained 4.0 ng of genomic DNA, $100 \mathrm{nM}$ of bidirectional primer, $2.5 \mathrm{mM}$ $\mathrm{MgCl}_{2}, 0.2 \mathrm{mM}$ dNTP, and 0.1 U HotStar Taq Polymerase (Quiagen $\mathrm{GmbH}$, Germany). The PCRs were performed as follows: 15 minutes of denaturation at $95^{\circ} \mathrm{C}$, followed by 45 cycles of denaturing for 20 seconds at $95^{\circ} \mathrm{C}$, annealing for 30 
Table 1. Demographic and clinical characteristics of ADHD probands and controls

\begin{tabular}{|c|c|c|c|c|}
\hline Characteristics & \multicolumn{2}{|c|}{ Probands $(\mathrm{N}=189)$} & \multicolumn{2}{|c|}{ Controls $(\mathrm{N}=150)$} \\
\hline Age (years) ${ }^{*}$ & \multicolumn{2}{|c|}{$9.2 \pm 2.3$} & \multicolumn{2}{|c|}{$9.4 \pm 0.6$} \\
\hline \multirow[t]{2}{*}{$\mathrm{IQ}^{*}$} & \multicolumn{2}{|c|}{$105.0 \pm 14.6$} & \multicolumn{2}{|c|}{$100.5 \pm 8.5$} \\
\hline & $\mathrm{N}$ & $\%$ & $\mathrm{~N}$ & $\%$ \\
\hline \multicolumn{5}{|l|}{ Sex } \\
\hline Male & 166 & 87.8 & 131 & 87.3 \\
\hline Female & 23 & 12.2 & 19 & 12.7 \\
\hline \multicolumn{5}{|l|}{ ADHD subtype } \\
\hline Combined & 115 & 60.8 & - & - \\
\hline Inattentive & 32 & 16.9 & - & - \\
\hline Hyperactive-impulsive & 15 & 7.9 & - & - \\
\hline $\begin{array}{l}\text { Not otherwise } \\
\text { specified }\end{array}$ & 27 & 14.3 & - & - \\
\hline \multicolumn{5}{|l|}{ Comorbid disorder } \\
\hline $\begin{array}{l}\text { Oppositional defiant } \\
\text { disorder }\end{array}$ & 18 & 9.5 & - & - \\
\hline Conduct disorder & 2 & 1.1 & - & - \\
\hline Mood disorder & 3 & 1.6 & - & - \\
\hline Anxiety disorder & 6 & 3.2 & - & - \\
\hline Enuresis & 6 & 3.2 & - & - \\
\hline
\end{tabular}

*mean \pm standard deviation. ADHD: attention-deficit/hyperactivity disorder

seconds at $56^{\circ} \mathrm{C}$, and extension for 1 minute at $72^{\circ} \mathrm{C}$; the final extension was performed for 3 minutes at $72^{\circ} \mathrm{C}$.

\section{Homogeneous MassEXTEND (hME)}

The PCR products were treated with $0.3 \mathrm{U}$ of shrimp alkaline phosphatase for 20 minutes at $37^{\circ} \mathrm{C}$, after which the enzymatic activity was inhibited for 5 minutes. The hME reaction was performed in a $9 \mu \mathrm{L}$ reaction mixture containing the hME enzyme (Thermosequenase, GE Healthcare, UK), ACT termination mix, and $5 \mu \mathrm{M}$ extension primers (T102C-E: 5'AGA AGT GTT AGC TTC TCC; G861C-E: 5'AAT CCG GAT CTC CTG TGT ATG T). The primer extension reaction was carried out in 55 cycles consisting of 2 minutes of denaturation at $94^{\circ} \mathrm{C}$, followed by 5 seconds at $94^{\circ} \mathrm{C}, 5$ seconds at $52^{\circ} \mathrm{C}$, and 5 seconds at $72^{\circ} \mathrm{C}$. The reaction products were desalted using SpectroCLEAN (Sequenom, Inc., CA), and a SpectroJET (Sequenom, Inc., CA) was used to spot a 384-well SpectroCHIP (Sequenom, Inc., CA). The prepared SpectroCHIP was analyzed using the automated MALDI-TOF MassARRAY system (Bruker-Sequenom, CA). Following automated peak calling, samples with bad call signs that could be confirmed using the naked eye were further analyzed.

\section{Statistical analysis}

To evaluate the demographic and clinical characteristics of the study subjects, Student's t-test was performed to compare the ages and IQs between the case group and control group, and a $\chi^{2}$ (chi-square) test was performed to compare the sexes. In addition, Student's t-test was used to analyze the results from the clinical scale and neuropsychological tests according to the genotypes of the case group.

Furthermore, a $\chi^{2}$ test was also performed to evaluate the association analysis between the case-control groups, whereas for the family-based association analysis, a TDT was performed using McNemar's $\chi^{2}$ test under the hypothesis that specific alleles are inherited more favorably. This study included only cases in which the patient-father-mother trio participated in the analyses.

SPSS 10.0 for Windows was used for the statistical analyses, and the significance level was set at $\mathrm{p}<0.05$.

\section{RESULTS}

\section{Demographic and clinical characteristics of the subject groups}

There was no significant differences between the age of case (9.2 \pm 2.3 years) and the control ( $9.4 \pm 0.6$ years)(Table 1$)$. With respect to the sex ratios, there were higher proportions of males in both groups ( $87.8 \%$ and $87.3 \%$, respectively). The overall IQ of the case group was $105.0 \pm 14.6$, which was not significantly different from that of the control group (100.5 \pm 8.5).

The comorbid disorders of the case group were as follows: oppositional defiant disorder $(9.5 \%)>$ anxiety disorder $(3.2 \%)=$ enuresis $(3.2 \%)>\operatorname{mood}$ disorder $(1.6 \%)$. A total of 5 subjects presented with more than two comorbid disorders, including 2 cases with both oppositional defiant disorder and anxiety disorder, 2 cases with both oppositional defiant disorder and enuresis, and 1 case with both conduct disorder and mood disorder.

\section{Case-control association analysis results}

Hardy-Weinberg equilibrium analysis of the genotype distributions of the target genes in the case group and control group revealed that equilibrium was maintained for both the case $\left(\chi^{2}=2.61, \mathrm{p}=0.106\right)$ and control group $\left(\chi^{2}=0.75, \mathrm{p}=0.387\right)$.

The frequency distribution of the 3 genotypes among the entire $\mathrm{ADHD}$ patient group and the control group did not reveal any statistical differences $(\mathrm{p}=0.078)$, though the $\mathrm{T} / \mathrm{C}$ type tended to appear more frequently in the patient group. Moreover, the frequency distributions of the groups according to the presence of $\mathrm{T}$ allele were also examined, and no statistical difference was detected between the case and the control gro- 
up ( $p=0.899)$. However, comparison of the distributions between the case and control groups according to the presence of $\mathrm{C}$ allele showed that there were significant differences $\left(X^{2}=4.73, p=0.030\right)$ between the groups with $(78.5 \%$ vs. $68.0 \%)$

Table 2. Comparison of the genotype and allele frequencies of T102C polymorphism of 5-HT2A receptor gene between ADHD probands and controls

\begin{tabular}{|c|c|c|c|c|c|}
\hline & \multicolumn{2}{|c|}{ Probands $(\mathrm{N}=186)$} & \multicolumn{2}{|c|}{ Controls $(\mathrm{N}=150)$} & \multirow{2}{*}{$\begin{array}{c}\mathrm{p} \\
\text { value }\end{array}$} \\
\hline & $\mathrm{N}$ & $\%$ & $\mathrm{~N}$ & $\%$ & \\
\hline \multicolumn{6}{|l|}{ Genotype } \\
\hline $\mathrm{T} / \mathrm{T}$ & 40 & 21.5 & 48 & 32.0 & \multirow{3}{*}{0.078} \\
\hline $\mathrm{T} / \mathrm{C}$ & 104 & 55.9 & 69 & 46.0 & \\
\hline $\mathrm{C} / \mathrm{C}$ & 42 & 22.6 & 33 & 22.0 & \\
\hline \multicolumn{6}{|l|}{ Allele } \\
\hline $\mathrm{T}$ & 184 & 49.5 & 165 & 55.0 & \multirow{2}{*}{0.153} \\
\hline $\mathrm{C}$ & 188 & 50.5 & 135 & 45.0 & \\
\hline \multicolumn{6}{|l|}{ Grouping ${ }^{\dagger}$} \\
\hline With T allele & 144 & 77.4 & 117 & 78.0 & \multirow{2}{*}{0.899} \\
\hline Without T allele & 42 & 22.6 & 33 & 22.0 & \\
\hline \multicolumn{6}{|l|}{ Grouping ${ }^{\ddagger}$} \\
\hline With C allele & 146 & 78.5 & 102 & 68.0 & \multirow{2}{*}{$0.030^{*}$} \\
\hline Without C allele & 40 & 21.5 & 48 & 32.0 & \\
\hline
\end{tabular}

Comparisons were conducted using $\chi^{2}$ (chi-square) test. ${ }^{*} \mathrm{p}<0.05$, tgenotype grouping according to the presence of $\mathrm{T}$ allele, ‡genotype grouping according to the presence of $\mathrm{C}$ allele. ADHD: attentiondeficit/hyperactivity disorder

Table 3. Comparison of the genotype and allele frequencies of T102C polymorphism of 5-HT2A receptor gene between the probands of ADHD combined type and controls

\begin{tabular}{|c|c|c|c|c|c|}
\hline & \multicolumn{2}{|c|}{ Probands $(\mathrm{N}=113)$} & \multicolumn{2}{|c|}{ Controls $(\mathrm{N}=150)$} & \multirow{2}{*}{$\begin{array}{c}\mathrm{p} \\
\text { value }\end{array}$} \\
\hline & $\mathrm{N}$ & $\%$ & $\mathrm{~N}$ & $\%$ & \\
\hline \multicolumn{6}{|l|}{ Genotype } \\
\hline $\mathrm{T} / \mathrm{T}$ & 22 & 19.5 & 48 & 32.0 & \multirow{3}{*}{$0.049^{*}$} \\
\hline $\mathrm{T} / \mathrm{C}$ & 67 & 59.3 & 69 & 46.0 & \\
\hline $\mathrm{C} / \mathrm{C}$ & 24 & 21.2 & 33 & 22.0 & \\
\hline \multicolumn{6}{|l|}{ Allele } \\
\hline $\mathrm{T}$ & 111 & 49.1 & 165 & 55.0 & \multirow{2}{*}{0.181} \\
\hline $\mathrm{C}$ & 115 & 50.9 & 135 & 45.0 & \\
\hline \multicolumn{6}{|l|}{ Grouping ${ }^{\dagger}$} \\
\hline With T allele & 89 & 78.8 & 117 & 78.0 & \multirow{2}{*}{0.882} \\
\hline Without $\mathrm{T}$ allele & 24 & 21.2 & 33 & 22.0 & \\
\hline \multicolumn{6}{|l|}{ Grouping $^{\ddagger}$} \\
\hline With C allele & 91 & 80.5 & 102 & 68.0 & \multirow{2}{*}{$0.023^{*}$} \\
\hline Without C allele & 22 & 19.5 & 48 & 32.0 & \\
\hline
\end{tabular}

Comparisons were conducted using $\chi^{2}$ (chi-square) test. ${ }^{*} \mathrm{p}<0.05$, tgenotype grouping according to the presence of $\mathrm{T}$ allele, ‡genotype grouping according to the presence of $\mathrm{C}$ allele. ADHD: attentiondeficit/hyperactivity disorder and without (21.5\% vs. $32.0 \%$ ) C allele (Table 2).

In addition, an association analysis was conducted between the control group and the combined-type ADHD subtype ( $n=113$ ), which was the ADHD subtype showing the highest distribution. The results indicated that there were significant differences $\left(\chi^{2}=6.02, \mathrm{p}=0.049\right)$ in the frequency distributions of the 3 genotypes between the case group (T/T 19.5\%, T/C $59.3 \%, \mathrm{C} / \mathrm{C} 21.2 \%$ ) and the control group (T/T 32.0\%, T/C $46.0 \%$, C/C 22.0\%). Furthermore, comparison of the distributions between the case and control groups according to alleles also showed that there were significant differences $\left(\chi^{2}=5.18\right.$, $\mathrm{p}=0.023)$ between the groups with $(80.5 \%$ vs. $68.0 \%)$ and without (19.5\% vs. $32.0 \%)$ C allele. However, there were no significant differences in allele frequency $(\mathrm{p}=0.181)$ or classification according to the presence of the $\mathrm{T}$ allele $(\mathrm{p}=0.882)$ (Table 3).

\section{Results of TDT analysis for families of ADHD patients}

To analyze the results of the TDT, Hardy-Weinberg equilibrium analyses were performed separately for the genotype distributions of the ADHD patient, father, and mother groups, revealing that Hardy-Weinberg equilibrium was maintained in each case (patient group: $\chi^{2}=1.65, p=0.199$; father group: $\chi^{2}=0.94, \mathrm{p}=0.333$; mother group: $\chi^{2}=1.65, \mathrm{p}=0.199$ ).

A TDT analysis was conducted on the entire family group of the patient-parent trios, but the selective transmission of a specific allele was not observed $(\mathrm{p}=1.000)$ (Table 4). Likewise, no selective transmission of a specific allele was observed in the trios $(n=66)$ of the combined-type ADHD patient families $(\mathrm{p}=0.718)$.

\section{$\mathrm{CPT}$ and $\mathrm{K}-\mathrm{CBCL}$ results in the patient group according to the presence of the $\mathrm{C}$ allele}

Based on the earlier finding of significant differences in the genotype distributions of the case and control groups according to the presence of the $\mathrm{C}$ allele, as revealed by the casecontrol analysis, we investigated the results of CPT and $\mathrm{K}$ CBCL according to the presence of the $\mathrm{C}$ allele in the ADHD patient group.

Table 4. Result of transmission disequilibrium test (TDT) of T102C polymorphism of 5-HT2A receptor gene in all ADHD trios

\begin{tabular}{llcc}
\hline & & \multicolumn{2}{c}{ Transmitted } \\
\cline { 3 - 4 } & & $\mathrm{C}$ & $\mathrm{T}$ \\
\hline Not transmitted & $\mathrm{C}$ & 62 & 54 \\
& $\mathrm{~T}$ & 54 & 50 \\
\hline
\end{tabular}

Comparison was conducted using McNemar's $\chi^{2}$ test. No significant biased transmission was found in TDT analysis of any allele $\left(\chi^{2}=0.00, \mathrm{df}=1, \mathrm{p}=1.000\right)$. ADHD: attention-deficit/hyperactivity disorder 
The age difference between the group with the $\mathrm{C}$ allele and without the $\mathrm{C}$ allele was not significant $(\mathrm{p}=0.243$ ). Moreover, there were no significant differences between the two groups regarding total IQ $(\mathrm{p}=0.874)$, verbal IQ $(\mathrm{p}=0.742)$, or performance IQ ( $p=0.333)$. However, the group with the $C$ allele presented significantly higher scores in the mean reaction time $(\mathrm{t}=2.956, \mathrm{p}=0.004)$ and in the standard deviation of reaction time $(\mathrm{t}=2.654, \mathrm{p}=0.009)$ of the auditory CPT compared with the group without the $\mathrm{C}$ allele, whereas the scores for the omission error $(t=-2.539, p=0.012)$ and commission error $(t=-2.820$, $\mathrm{p}=0.007$ ) tests of the visual CPT were significantly lower in the group with the $\mathrm{C}$ allele compared the group without the $\mathrm{C}$ allele. Furthermore, the group with the $\mathrm{C}$ allele showed a significantly lower score compared with the group without $\mathrm{C}$ allele on the externalizing symptoms subscale $(\mathrm{t}=-2.316, \mathrm{p}=$ 0.022) of the K-CBCL (Table 5).

\section{DISCUSSION}

With respect to the comorbid disorders in the subject groups in this study, oppositional defiant disorder was observed at a frequency of $9.8 \%$, whereas the other 4 disorders (anxiety disorder, enuresis, mood disorder, and conduct disorder) were found at minimum and maximum frequencies of $1.1 \%$ and $3.2 \%$, respectively. However, we believe that the results of the present study adequately reflected the genetic ef- fects of ADHD, because the frequency of comorbid disorders in our study population was comparatively lower than that in previous genetic studies about 5-HT2A in ADHD. ${ }^{26,27}$

The most significant results of this study came from the association analysis, which revealed that there was a significantly higher proportion of genotypes that included the $\mathrm{C}$ allele $(\mathrm{C} / \mathrm{C}$ and $\mathrm{T} / \mathrm{C})$ in the case group compared with the control group. Furthermore, this difference was more noticeable when the case group was limited exclusively to the combinedtype patients rather than the entire ADHD group, and the significant difference of the proportion of 3 genotypes were observed in the combined-type patients only. Todd et al. reported that DSM-IV combined-type ADHD might be a genetically homogeneous subgroup. ${ }^{28}$ Furthermore, from the point of sibling risk ratio, the risk of combined-type ADHD was slightly higher than that of broadly defined ADHD. ${ }^{29}$ Therefore, the results of combined-type ADHD in our study demonstrate the importance of $\mathrm{C}$ allele more remarkably.

Most of the previous studies involving the T102C polymorphism were family-based, whereas few case-control studies have investigated this polymorphism. However, in a group of Chinese Han subjects, Li et al. ${ }^{17}$ reported results that were notably similar to those of our study. In particular, the combinedtype genotype distributions of the case and control groups were $22.3 \%$ vs. $33.5 \%$ for the T/T type and $64.0 \%$ vs. $47.3 \%$ for the T/C type, respectively, and thus similar genotype dis-

Table 5. Comparisons of the scores of the CPT and K-CBCL tests between ADHD probands with $\mathrm{C}$ allele and without $\mathrm{C}$ allele in T102C polymorphism of 5-HT2A receptor gene

\begin{tabular}{|c|c|c|c|c|}
\hline & Proband with $\mathrm{C}$ allele & Proband without $\mathrm{C}$ allele & $\mathrm{t}$ & $\mathrm{p}$ value \\
\hline \multicolumn{5}{|l|}{ IQ score } \\
\hline Verbal & $105.6(14.1)^{\dagger}$ & $104.7(17.1)$ & 0.331 & 0.742 \\
\hline Performance & $102.0(13.4)$ & $104.7(15.6)$ & -0.610 & 0.333 \\
\hline Total & $104.3(13.8)$ & $104.7(16.9)$ & -0.159 & 0.874 \\
\hline \multicolumn{5}{|l|}{$\mathrm{CPT}$} \\
\hline Visual-omission errors & $76.9(37.3)$ & $95.8(40.0)$ & -2.539 & $0.012^{*}$ \\
\hline Visual-commission errors & $75.0(31.0)$ & $99.9(49.3)$ & -2.820 & $0.007^{* *}$ \\
\hline Visual-reaction time & $54.3(15.0)$ & $51.2(15.4)$ & 1.057 & 0.292 \\
\hline Visual-standard deviation of reaction time & $80.4(32.3)$ & $103.4(67.1)$ & -1.969 & 0.056 \\
\hline Auditory-omission errors & $60.8(18.9)$ & $61.7(18.5)$ & -0.249 & 0.803 \\
\hline Auditory-commission errors & $60.7(21.5)$ & $65.2(30.5)$ & -0.252 & 0.353 \\
\hline Auditory-reaction time & $56.5(17.6)$ & $45.8(19.3)$ & 2.956 & $0.004^{* *}$ \\
\hline Auditory-standard deviation of reaction time & $64.5(15.1)$ & $56.7(14.0)$ & 2.654 & $0.009^{* *}$ \\
\hline \multicolumn{5}{|l|}{ K-CBCL } \\
\hline Internalizing symptoms & $55.7(10.0)$ & $56.1(8.8)$ & -0.235 & 0.815 \\
\hline Externalizing symptoms & $57.2(10.9)$ & $62.5(9.6)$ & -2.316 & $0.022^{*}$ \\
\hline Total symptoms & $58.6(9.6)$ & $61.6(7.7)$ & -1.490 & 0.139 \\
\hline
\end{tabular}

Comparisons were conducted using independent T-test. ${ }^{*} \mathrm{p}<0.05,{ }^{* *} \mathrm{p}<0.01,{ }^{\dagger}$ mean \pm standard deviation. CPT: Continuous Performance Test, K-CBCL: Korean Child Behavior Checklist, ADHD: attention-deficit/hyperactivity disorder 
tributions and percentages were revealed. Other studies that treated issues related to the $\mathrm{T} 102 \mathrm{C}$ polymorphism ${ }^{14,16}$ were on Caucasian subjects and did not suggest any significant results. Both the previous studies and our present study suggest that the T102C polymorphism of the 5-HTR2A gene shows significant differences between the ADHD case and control groups but only in the northeast Asian population.

No selective transmission of the $\mathrm{T}$ or $\mathrm{C}$ allele within families was observed in the TDT performed in the present study. A review of previous studies showed that significant selective transmission of the $\mathrm{T}$ or $\mathrm{C}$ allele has also not been observed in Caucasian subjects; however, selective transmission of the His452 allele of the His452Tyr polymorphism within families has been reported. ${ }^{14,15}$ In contrast, a study by Li et al. detected selective transmission of the $\mathrm{C}$ allele in families of female combined-type patients using the TDT (195 trio). Similarly, in the present study, the TDT conducted on trios $(n=13)$ for the entire female ADHD group revealed a tendency to transmit the $\mathrm{C}$ allele, although the results were not statistically significant ( $\mathrm{p}=0.08)$.

However, not only was the presence of the $\mathrm{C}$ allele important regarding the differences in distribution between the case and control groups, but also when the score of CPT and KCBCL were compared within the ADHD patient group, the group with the $\mathrm{C}$ allele and the group without the $\mathrm{C}$ allele showed different results. Therefore, caution is necessary in interpreting these results.

First, the group without the $\mathrm{C}$ allele exhibited significantly higher omission and commission errors in visual attention compared with the group with the $\mathrm{C}$ allele, and the externalizing symptoms in K-CBCL were also significantly high. With respect to this idea, Bjork et al..$^{30}$ conducted a study on normal subjects without $\mathrm{ADHD}$ and reported on the results of the $\mathrm{CPT}$ with regards to the $\mathrm{T} 102 \mathrm{C}$ polymorphism. These researchers reported that the visual commission error score from the $\mathrm{CPT}$ was significantly higher for the $\mathrm{T} / \mathrm{T}$ genotype compared to the T/C and C/C genotypes. Although these researchers used unaffected individuals as subjects, their results were similar to those of our study in terms of visual attention.

What is even more significant in the present study is that the mean reaction time and standard deviation of the reaction time for the auditory CPT were higher in the group with the $\mathrm{C}$ allele compared to the group without the $\mathrm{C}$ allele.

There have been various studies performed focusing on modality-specific attention problems, such as visual attention and auditory attention. For example, Cooley and Morris ${ }^{31}$ claimed that attention is specific to each sensory system, i.e., the visual, auditory, and verbal systems. Bedi et al..$^{32}$ noted that among normal children, those children who display 'visual distractibility' have a significant correlation between vi- sual distractibility and the inattentiveness reported by teachers; however, those children who display auditory distractibility have significant correlations between auditory distractibility and academic achievement. Moreover, there have been a number of reports that some ADHD children are classified as having the 'central auditory processing disorder. ${ }^{33,34}$ In particular, the neurophysiological studies on the relationship between serotonergic substances and the auditory attentiveness are in the spotlight. Research on the association between serotonergic substances and auditory attentiveness using a method measuring auditory selective attention while conducting tryptophan depletion tests revealed that serotonin is associated with the modulation of auditory attention. ${ }^{35}$ Therefore, our findings in the present study most likely suggest that the existence of the $\mathrm{C}$ allele in $\mathrm{ADHD}$ causes variation in the serotonergic system that negatively affects auditory attention in particular. In other words, we think that the T102C polymorphism is associated with the modality-specific attention problems observed in ADHD.

However, there may be another reason for such complex results. As stated in the introduction, if the dopaminergic and noradrenergic systems are directly impacts the manifestation of ADHD, the serotonergic 5-HTR2A gene does not have a direct effect but rather affects the manifestation of ADHD by modulating the dopaminergic system, which may have resulted in these complex findings.

Considering clinical treatment in conjunction with the results of this study, it should be noted that the mechanism of action for atypical antipsychotics, which are another choice in drug treatment for children and adolescents, involves not only the dopaminergic system but also the serotonergic system. For instance, the typical mechanism of action of risperidone is to block DR2 and 5-HTR2A, so risperidone is classified as a serotonin-dopamine antagonist. Additionally, aripiprazole, which is known to have both dopaminergic partial agonist effects and 5-HTR2A blocking effects, has recently been shown to be slightly effective in treating ADHD. ${ }^{36,37}$ This finding suggests that interactions between the serotonergic and dopaminergic systems are very important in ADHD. Of course, not all children with ADHD benefit from treatment with risperidone or aripiprazole compared with methylphenidate, but a subgroup with a far superior reaction to these drugs may exist, and the $\mathrm{C}$ allele may be included as one of the markers for such a subgroup.

There were several limitations of this study. First, there were a total of 189 patients and 115 trio subjects in the patient and family groups, which is significantly lower than the ideal study population size. The use of a small number of subjects has also caused problems in previous similar studies, as parental cooperation is not easy to obtain when study subjects are chil- 
dren or adolescents, rather than adults. Although 4 university hospitals participated in the study together, a true multi-center study that includes more hospitals will be necessary in the future.

Second, out of the three types of genetic polymorphisms that have been reported in 5-HTR2A, only T102C was examined in this study. Thus, the possibility of obtaining a different result cannot be ruled out if a candidate gene is selected from a different genetic locus.

Third, the only neuropsychological testing selected in the present study was the CPT. If we had conducted more elaborate neuropsychological tests by performing other important tests in addition to the CPT, we may have been able to identify differences in the neuropsychological test results according to each genotype more impartially.

Despite these limitations, this study is significant in the following respects: this study conducted a case-control study and a family-based association study for the gene polymorphism of 5-HTR2A that focused on the serotonergic system transmission, which has rarely been reported in Korean ADHD children; this study discovered that significant differences were found depending on the presence of the $\mathrm{C}$ allele, and the patient group showed differences in modality-specific attention depending on the presence of the $\mathrm{C}$ allele. These results may be useful for future studies addressing ADHD treatment methods and for selecting drugs that affect the interactions between the dopaminergic and serotonergic systems or the norepinephrinergic and serotonergic systems. It is our hope that the limitations of this study will be overcome in the future and that there will be breakthroughs in elucidating the causes of ADHD as well as in improving treatment options, early intervention, subtype detection, and diagnosis related to this disease through genetic research on a wider variety of components involved in the serotonergic system.

\section{Acknowledgments}

This work was supported by the research grant of the Chungbuk National University in 2010.

\section{REFERENCES}

1. Franke B, Neale BM, Faraone SV. Genome-wide association studies in ADHD. Hum Genet 2009;126:13-50.

2. Purcell S, Sham P, Daly MJ. Parental phenotypes in family-based association analysis. Am J Hum Genet 2005;76:249-259.

3. Spierman RS, McGinnis RE, Ewens WJ. Transmission test for linkage disequilibrium: the insulin gene region and insulin-dependent diabetes mellitus (IDDM). Am J Hum Genet 1993;52:506-516.

4. Cho SC, Kim JW, Kim BN, Hwang JW, Park M, Kim SA, et al. Possible association of the alpha-2A-adrenergic receptor gene with response time variability in attention deficit hyperactivity disorder. Am J Med Genet B Neuropsychiatr Genet 2008;147B:957-963.

5. Cho SC, Kim JW, Kim BN, Hwang JW, Shin MS, Park M, et al. Association between the alpha-2C-adrenergic receptor gene and attention deficit hyperactivity disorder in a Korean sample. Neurosci Lett 2008;446:
108-111.

6. Halperin JM, Newcorn JH, Kopstein I, McKay KE, Schwartz ST, Siever LJ, et al. Serotonin, aggression, and parental psychopathology in children with attention-deficit hyperactivity disorder. J Am Acad Child Adolesc Psychiatry 1997;36:1391-1398.

7. Halperin JM, Neweorn JH, Schwartz ST, Sharma V, Siever LJ, Koda $\mathrm{VH}$, et al. Age-related changes in the association between serotonergic function and aggression in boys with ADHD. Biol Psychiatry 1997;41: 682-689.

8. Gainetdinov RR, Wetsel WC, Jones SR, Levin ED, Jaber M, Caron MG. Role of serotonin in the paradoxical calming effect of psychostimulants on hyperactivity. Science 1999;283:397-401.

9. Quist JF, Kennedy JL. Genetics of childhood disorders XXIII. ADHD, Part 7: the serotonin system. J Am Acad Child Adolesc Psychiatry 2001; 40:253-256.

10. O’Neill MF, Heron-Maxwell CL, Shaw G. 5-HT2 receptor antagonism reduces hyperactivity induced by amphetamine, cocaine, and MK-801 but not D1 agonist C-APB. Pharmacol Biochem Behav 1999;63:237243.

11. Stahl SM. Stahl's Essential Psychopharmacology, 3rd Edition. New York: Cambridge University Press; 2008.

12. Collier DA, Arranz MJ, Li T, Mupita D, Brown N, Treasure J. Association between 5-HT2A gene promoter polymorphism and anorexia nervosa. Lancet 1997;350:412.

13. Erdmann J, Shimron-Abarbanell D, Rietschel M, Albus M, Maier W, Korner J, et al. Systematic screening for mutations in the human serotonin-2A (5-HT2A) receptor gene: identification of two naturally occurring receptor variants and association analysis in schizophrenia. Hum Genet 1996;97:614-619.

14. Masellis M, Basile V, Meltzer HY, Lieberman JA, Sevy S, Macciardi FM, et al. Serotonin subtype 2 receptor genes and clinical response to clozapine in schizophrenia patients. Neuropsychopharmacology 1998;19: 123-132.

15. Quist JF, Barr CL, Schachar R, Roberts W, Malone M, Tannock R, et al. Evidence for the serotonin HTR2A receptor gene as a susceptibility factor in attention deficit hyperactivity disorder (ADHD). Mol Psychiatry 2000;5:537-541.

16. Hawi Z, Dring M, Kirley A, Foley D, Kent L, Craddock N, et al. Serotonergic system and attention deficit hyperactivity disorder (ADHD): a potential susceptibility locus at the 5-HT(1B) receptor gene in $273 \mathrm{nu}$ clear families from a multi-centre sample. Mol Psychiatry 2002;7:718725.

17. Zoroglu SS, Erdal ME, Erdal N, Ozen S, Alasehirli B, Sivasli E. No evidence for an association between the T102C and $1438 \mathrm{G} / \mathrm{A}$ polymorphisms of the serotonin 2A receptor gene in attention deficit/hyperactivity disorder in a Turkish population. Neuropsychobiology 2003;47: 17-20.

18. Li J, Wang Y, Qian Q, Wang B, Zhou R. Association of 5-HT(2A) receptor polymorphism and attention deficit hyperactivity disorder in children. Zhonghua Yi Xue Za Zhi 2002;82:1173-1176.

19. American Psychiatric Association. Diagnostic and Statistical Manual of Mental Disorders, 4th Edition. Washington DC: American Psychiatric Press; 1994.

20. So YK, Noh JS, Kim YS, Ko SG, Koh YJ. The reliability and validity of Korean parent and teacher ADHD rating scale. J Korean Neuropsychiatr Assoc 2002;41:283-289.

21. Sattler JM. Assessment of Children's Intelligence. Philadelphia: WB Saunders Company; 1974.

22. Kaufman J, Birmaher B, Brent D, Rao U, Flynn C, Moreci P, et al. Schedule for Affective Disorders and Schizophrenia for School-Age Children-Present and Life Time Version (K-SADS-PL): initial reliability and validity data. J Am Acad Child Adolesc Psychiatry 1997;36:980988.

23. Park M, Yoon J, Park H, Park H, Kwon K. KEDI-WISC. Seoul: Special Education Publishing Co; 1987. 
24. Achenbach TM, Edelbrock C. Manual for the Child Behavior Checklist/4-18 and 1991 Profile. Burlington, VT: University of Vermont; 1991.

25. Shin MS, Cho SZ, Chun SY, Hong KE. A study of the development and standarization of ADHD diagnostic system. Korean J Child Adolesc Psychiatry 2000;11:91-99.

26. Roman T, Schmitz M, Polanczyk GV, Eizirik M, Rohde LA, Hutz MH. Is the alpha-2A adrenergic receptor gene (ADRA2A) associated with attention-deficit/hyperactivity disorder? Am J Med Genet B Neuropsychiatr Genet 2003;120:116-120.

27. Li J, Wang Y, Zhou R, Zhang H, Yang L, Wang B, et al. Serotonin 5-HT1B receptor gene and attention deficit hyperactivity disorder in Chinese Han subjects. Am J Med Genet B Neuropsychiatr Genet 2005; 132B:59-63.

28. Brookes K, Xu X, Chen W, Zhou K, Neale B, Lowe N, et al. The analysis of 51 genes in DSM-IV combined type attention deficit hyperactivity disorder: association signals in DRD4, DAT1 and 16 other genes. Mol Psychiatry 2006;11:934-953.

29. Todd RD, Lobos EA, Sun LW, Neuman RJ. Mutational analysis of the nicotinic acetylcholine receptor alpha 4 subunit gene in attention deficit/hyperactivity disorder: evidence for association of an intronic polymorphism with attention problems. Mol Psychiatry 2003;8:103-108.
30. Bjork JM, Moeller GM, Dougherty DM, Swann AC, Machado MA, Hanis CL. Serotonin 2A receptor T102C polymorphism and impaired impulse control. Am J Med Genet 2002;114:336-339.

31. Cooley EL, Morris RD. Attention in children: a neuropsychologically based model for assessment. Dev Neuropsychol 1990;6:239-274.

32. Bedi GC, Halperin JM, Sharma V. Investigation of modality-specific distractibility in children. Int J Neurosci 1994;74:79-85.

33. Keith RW, Engineer P. Effect of methylphenidate on the auditory processing abilities of children with attention deficit-hyperactivity disorder. J Learn Dis 1991;24:630-636.

34. Lucker JR, Geffner D, Koch W. Perception of loudness in children with ADD and without ADD. Child Psychiatry Hum Dev 1996;26:181-190.

35. Ahveninen J, Jääskeläinen IP, Pennanen S, Liesivuori J, Ilmoniemi RJ, Kähkönen S. Auditory selective attention modulated by tryptophan depletion in humans. Neurosci Lett 2003;340:181-184.

36. Findling RL, Short EJ, Leskovec T, Townsend LD, Demeter CA, McNamara NK, et al. Aripiprazole in children with attention-deficit/hyperactivity disorder. J Child Adol Psychopharmacol 2008;28:347-354.

37. Lim MH, Kang JK, Park TW, Paik KC, Kim HW. Aripiprazole in ADHD with tic disorder and in ADHD with Tourette disorder: two case reports. Clin Psychopharmacol Neurosci 2007;5:81-84. 